\title{
Multiple Linear Regression Analysis of Marketable Supply of Beef Cattle in Kaffa Zone Southern Ethiopia
}

\author{
Gedefaw Abebe Abiye* \\ ${ }^{*}$ College of Agriculture and Natural Resource, Department of Agricultural Economics \\ Bonga University P.O. Box: 334, Bonga, Ethiopia
}

\begin{abstract}
The share of meat and other slaughter by-products exported from the overall export commodities is not more than $2 \%$ and meat consumption is below the average of Sub-Sahara African countries. So, marketable supply of beef cattle have important role in making better income for smallholder farmers. As a result the study was aimed to investigate the impediment that affects beef cattle marketable supply in Gimbo district. Two- stage sampling technique was employed to pick up 196 target sample respondents from the sample frame in the study area. Multiple linear regression models were used for analysis. As the model result indicates: marketable supply of beef cattle were affected positively by: number of livestock fattened, sex of household head, perception of current price, access to credit, area of land allocated for grazing ,access to market information and educational status. So, improvement of fattening management systems should be taken in to consideration to increase marketable supply of beef cattle in the study area as well as at country level.
\end{abstract}

Keywords: marketable supply, beef cattle, multiple linear regression models, Gimbo, Ethiopia

DOI: $10.7176 / F S Q M / 98-02$

Publication date:June $30^{\text {th }} 2020$

\section{Background}

International markets, fast-growing, middle and high income classes in many developing countries offer opportunities for developing country producers in national and international markets (Ponguru et al., 2015). Trades of live animals are a major component of the agricultural sector in Sub-Saharan Africa (Motta et al., 2019). Meat and other slaughter by-products being exportable to the foreign export earnings and GDP growth of Ethiopia. Even though, the share of meat and other slaughter by-products exported from the overall export commodities is not more than $2 \%$ and meat consumption is below the average of Sub-Sahara African countries (Tekeba et al., 2018).

Ethiopia has the largest livestock population and the highest draft animal population in the continent i.e approximately 35 million cattle, 48 million sheep and 8.6 million equine goats, in the country (Ponguru et al., 2015, Amistu et al., 2016, CSA, 2013). Despite the largest number of beef cattle population in the country, it lacks strategic and market-oriented production system which failed to assist in transforming subsistence farming system into a commercial production system (Solomon et al., 2019 and Sitti Nurani Sirajuddin et al., 2015).

The cattle markets in most parts of Ethiopia are characterized by seasonality in flow and prices. For instance in pastoral lowland areas major factors contribute to seasonal flow include festivals, weather, pasture, seasonality of consumption demand (Zekarias et al., 2018).

As a result subsistence oriented and very low productivity of cattle becomes challenge in Ethiopia (Eyob and Zewudu, 2016). This lead to loss of: foreign exchange, income taxes and legal livestock trade. So, changing this bottle neck may lead to more rapid herd and animal growth, profitability of farmers and pastoral society's living standard scale up. Moreover animals are not managed for meat production as the required level due to bulky and costly nature of cattle to transport (Gezehagn et al., 2019 and Wenying Li et al., 2019).

The supply statuses of beef cattle are depending on the season of the year: i.e during holiday and time for paying cost of inputs like fertilizers and pesticides (Tamrat, 2019) .Due to this price of beef cattle dramatically increasing which is opposite demand of consumers. The high price of beef was influenced by many factors: one of the factors was low performance of beef cattle supply chain management (Sitti Nurani Sirajuddin et al., 2015).

Many empirical studies were done (Such as: Amistu et al., 2016; Dinku et al., 2019; Gemechu et al.,2020; Gezahegn et al., 2019; Solomon et al., 2019; Ponguru et al., 2015; Sicelo et al., 2019; Tamrat ,2019 and Sitti Nurani Sirajuddin et al., 2015) in different areas with different discipline. Even if those studies were done, additional empirical studies would be needed to increase beef cattle marketable supply in the country, specifically in the study area. So, this study was aimed to identify factors affecting marketable supply of beef cattle to provide useful insights towards the designing and implementation of strategies to alleviate the shortage of beef cattle supply to the market which in turn meet the demand of domestic consumption and export market.

\section{Research methodology}

2.1 Description of the study area

This study was conducted in Gimbo district which is one of the district in southern nations, nationalities and 
peoples regional state of Ethiopia, part of Keffa zone. The district is located at 440 kilometer from Addis Ababa and $9 \mathrm{~km}$ from Bonga. The district bordered in south by Decha district, in west by Chena, in north by Gojeb River and in east by Menjiwo. The elevation of this district ranges from 3300 to 4300 meter above the Sea level. The total population of the district is 89892 of whom 44774 are men and 45118 women (CSA, 2014) Ethiopian population census. $81.32 \%$ the population were orthodox Christians, $13.67 \%$ were catholic and $2.13 \%$ were Muslims. In other ways $85 \%$ of the populations are rural dwellers' and 15\%' are urban dwellers' (GDO, 2019).

\subsection{Sampling techniques and sample Size}

Two- stage sampling technique was employed for this study. In the first stage thirty five smallest administrative units were purposely selected based on livestock production potential among thirty nine smallest administrative units (kebeles) in Gimbo district. In second stage five kebeles were selected by simple random sample methods from 35 rural kebeles. Finally 196 sample sizes were determined by using Cochran's (1963) formula. i.e $n=$ $z^{2} \frac{p q}{e^{2}}$, Where, $\mathrm{n}=$ sample size, $\mathrm{p}=$ population proportion, $\mathrm{e}=$ level of precision, $\mathrm{z}=$ level of confidence, $i . e$ $n=$ $1.96^{2} \frac{0.5 * 0.5}{(0.07)^{2}}=196$.

\subsection{Data collection and analysis}

Primary and secondary data were used. Descriptive statistics and multiple linear regression models were employed for analysis and STATA 14 was used as a tool of analysis.

\subsection{Multiple linear regression model specification}

Regression of independent variables on one dependent variable is called multiple regression model (Kaya \& Guler, 2013). Rather than modeling as a simple regression, better to model dependent variable as a function of several explanatory variables (Gemechu et al., 2020).

Multiple linear regression model (MLRM) is selected for its simplicity and practical applicability (Greene, 2003 and Dessie et al., 2019). Moreover this model is used to test both economic theories and non-experimental data because it can accommodate many cause variables which may be correlated (Maddala and Lahiri, 1992). Unlike simple regression analysis, multiple linear regression analysis is more responsive to ceteris paribus analysis because it allows us to explicitly control many other factors which simultaneously affect effect variable .So, multiple linear regression models were used to analyze factors affecting beef cattle marketable supply in Gimbo district for this study.

The functional relationship of MLRM: $y=f(x 1, x 2, x 3, \ldots, x n, E m)$

Where $\mathrm{y}=$ beef cattle marketable supply, $\mathrm{xn}=$ cause variables and $\mathrm{\varepsilon m}=$ error terms

MLRM: $y=\alpha+\beta 1 x 1+\beta 2 x 2+\beta 3 x 3+\cdots+\beta n x n+\mathrm{Em}$.

Where $\mathrm{y}=$ effect variable, $\mathrm{Xn}=$ cause variables, $\alpha=$ constant, $\beta \mathrm{n}=$ parameters associated with cause variable and $\varepsilon \mathrm{k}=$ error terms.

Table1 Description and working hypothesis of variables in MLRM

\begin{tabular}{|l|l|l|l|l|}
\hline \multicolumn{2}{|l|}{} & Descriptions & $\begin{array}{l}\text { Nature } \\
\text { variables }\end{array}$ & Sign \\
\hline DV & Dependent variable & Continous & & \\
\hline IV & Independent variables & & & \\
\hline AGE & Age of household head & Continous & Year & + \\
\hline SEX & Sex of household head & Dummy & $1=$ male, $0=$ female & + \\
\hline EHH & Education of the house head & Continous & Grade & + \\
\hline FS & Family size & Continuous & Adult equivalent & $+/-$ \\
\hline LAFG & Land allocated for grassing & Continous & In hectare & + \\
\hline TNLU & Total livestock in the family & Continous & TLU & - \\
\hline MS & $\begin{array}{l}\text { Marital status of house hold } \\
\text { head }\end{array}$ & Dummy & 1 for married, 0 otherwise & + \\
\hline PCP & Perception of current price & Perception & Index & Favorable \\
\hline NLF & Number of livestock fattened & Continous & TLU & + \\
\hline FEC & $\begin{array}{l}\text { Frequency of extension } \\
\text { contact }\end{array}$ & Continuous & In number & + \\
\hline DTM & Distance to the market center & Continous & Walking in minute & - \\
\hline ATC & Access of credit & Dummy & 1 for access of credit, 0 otherwise & + \\
\hline AMI & Access of market information & Dummy & $\begin{array}{l}1 \text { for access of information, } 0 \\
\text { otherwise }\end{array}$ & + \\
\hline
\end{tabular}




\subsection{Diagnosis tests}

Before multiple linear regression models were analyzed: multicollinearity tests were conducted to identify the variables that are highly correlated. As (Gujarati, 2004) variance inflation factor (VIF) is used to check multicollinearity among continuous variables before including variables in the model. As a rule of thumb, if the value of VIF is greater than 10, the variables are said to be highly collinear. Likewise, the multicollinearity between discrete variables can be calculated using contingency coefficient (CC). The value ranges between 0 and 1,0 indicating no association between the variables and value close to 1 indicating a high degree of association between variables. As a rule of thumb, if the value of $\mathrm{CC}$ is greater than 0.75 , the variables are said to be collinear.

\section{Results and discussions}

\subsection{Descriptive statistics results for continues variables}

The mean age of household head is about 46 years with standard deviation 11.2 meaning majority of them were productive age Table 2. The average family sizes for livestock producers were 5 persons per household almost similar to the national average which is 5.1 per household (CSA, 2013). So, family size is a peculiar trait in rural societies of many developing countries such as Ethiopia (Shumetie and Mamo, 2019). The average educational status of respondents was 4.58 with standard deviation of 4.29. Thus educations contribute to improve beef cattle marketable supply. The average grazing land of sampled farmers is found to be 4.3 hectare which is greater than the national average i.e 1.37 hectare but it varies from place to place as (CSA, 2013). The average of livestock holding per household was 6.61 with standard deviation of 3.96 in the study area.

\section{Table 2 Descriptive results for continues variables}

\begin{tabular}{|l|l|l|l|l|}
\hline Cause variables & Minimum & Maximum & Mean & Standard deviation \\
\hline Age of Household head & 26 & 71 & 46.1 & 11.02 \\
\hline family size & 2 & 9 & 5 & 1.001 \\
\hline Educational status & 0 & 12 & 4.58 & 4.29 \\
\hline Farm size for grassing & 0.75 & 11 & 4.31 & 1.74 \\
\hline Total area of land & 0.5 & 3 & 1.29 & .538 \\
\hline Number of beef cattle fattened & 3.25 & 17.00 & 7.84 & 3.34 \\
\hline Total livestock holding & 1.3 & 23.36 & 6.61 & 3.96 \\
\hline
\end{tabular}

(Own survey, 2019)

Among 196 target respondents: 139 were male and the remaining 57 were female headed household Table 3. The marital statuses of sample respondents were $84.6 \%$ married, $15.4 \%$ single. From 196 sample respondents' $81.5 \%$ access to credit and $18.5 \%$ not access to credit service. Moreover $90.8 \%$ of the respondents' access market information while $9.2 \%$ not access market information.

Table 3 Descriptive result for dummy variables

\begin{tabular}{|c|c|c|c|}
\hline Dummy variables & Total sample & chi 2-value & Sign -value \\
\hline & $\mathrm{N} \quad \%$ & & \\
\hline $\begin{array}{ll}\text { Sex } & \begin{array}{l}\text { Female } \\
\text { Male }\end{array} \\
\end{array}$ & $\begin{array}{lc}57 & 29.02 \\
139 & 70.8 \\
\end{array}$ & 1.66 & 0.197 \\
\hline $\begin{array}{l}\text { Marital status } \\
\text { Single } \\
\text { Married } \\
\end{array}$ & $\begin{array}{ll}30 & 15.4 \\
166 & 84.6 \\
\end{array}$ & 2.47 & 0.116 \\
\hline $\begin{array}{c}\text { Access of credit } \\
\text { No } \\
\text { Yes } \\
\end{array}$ & $\begin{array}{l}36 \\
160 \\
\end{array}$ & 7.23 & $0.007 * * *$ \\
\hline $\begin{array}{c}\text { Access to market information } \\
\text { No } \\
\text { Yes }\end{array}$ & $\begin{array}{lc}18 & 9.2 \\
178 & 90.8 \\
\end{array}$ & 1.924 & 0.165 \\
\hline
\end{tabular}

Note: $* * *$ indicate at $1 \%$ level of significance

(Own survey, 2019)

\subsection{Econometric model result}

Before model analysis, diagnosis tests were carried out i.e the mean value of VIF is 1.32 which is less than 10 and Contingency Coefficient (CC) value less than 0.75 indicate there is no serious correlation among the suggested explanatory variables. As a result, thirteen cause variables were included for estimation to identify factors affecting beef cattle Marketable supply of target respondents in the study area. 
Table 4 multiple linear regression model result

\begin{tabular}{|l|l|l|l|}
\hline Variables & Coef. & Std. Err. & P $>|\mathrm{t}|$ \\
\hline AGE & .0095 & .0124 & 0.443 \\
\hline SEX & $.8473^{* *}$ & .3236 & 0.010 \\
\hline EHH & $.1924^{*}$ & .1115 & 0.087 \\
\hline FS & -.2183 & .1525 & 0.154 \\
\hline LAFG & $.7488^{* *}$ & .2869 & 0.010 \\
\hline TNLU & .0311 & .0347 & 0.371 \\
\hline MS & $.3363^{* * *}$ & .0427 & 0.000 \\
\hline PCP & $.6692^{* * *}$ & .2519 & 0.009 \\
\hline NLF & $.8053^{* * *}$ & .1204 & 0.000 \\
\hline FEC & -.0684 & .1244 & 0.583 \\
\hline DTM & .0109 & .0917 & 0.905 \\
\hline ATC & $1.022^{* * *}$ & .2767 & 0.000 \\
\hline AMI & $.6985^{* *}$ & .2907 & 0.017 \\
\hline cons & .0580 & 1.153 & 0.960 \\
\hline F statistics & 0.0000 & & \\
\hline$R^{2}$ & $80.27 \%$, & & \\
\hline Adj R & & & \\
\hline
\end{tabular}

Note: $* * *, * * \& *$ indicate $1 \%, 5 \%$ and $10 \%$ level of significance respectively

(Own survey, 2019)

Sex of the household head (SHH): this variable affected beef cattle marketable supply positively at $5 \%$ level of significance. This implies that as compared with female household head, male household head can increase marketable supply of beef cattle by 0.8473 positively due to the fact that males have relatively better labor advantage to produce and supply as compared female household head. This result in line with (Gezehagn et al., 2019) determinants of market participation and supply of beef cattle value chain as well as (Sicelo et al., 2019) double hurdle estimation of sales decisions by smallholder beef cattle farmers in Eswatini positively.

Education of the household head (EHH): this variable affects marketable supply of beef cattle positively at $10 \%$ significance level. This implies that an increase in year of schooling by one year, beef cattle supply increased by 0.1924 . This is in line with (Gemechu et al., 2020, Dinku et al., 2019) factor affecting beef cattle value chain analysis and (H. D. Utami et al, 2018) determinants affecting small holder beef cattle farmers' income.

Number of livestock fattened (NLF): this variable affect marketable supply positively at $1 \%$ significance level. If the number of livestock fattened increase by one number leads an increase beef cattle marketable supply by 0.3363. This finding is in line with (Dinku et al., 2019) marketable surplus of paddy is positively related to the volume of production.

Land allocated for grazing (LAFG): the estimated coefficient of this variable was found to be affect marketable supply positively at $5 \%$ significance level. If land allocated for grazing increase by one hectare, number of beef cattle supplied to the market increase by 0.7488 . This indicates farmers, who have more farm size most likely to supply beef cattle. This result go with (Dinku et al., 2019) farmers who have more farm size, are most likely to produce sesame, in turn increase marketable supply.

Perception of current price (PCP): this variable affects marketable supply of beef cattle positively at $1 \%$ significance level. This implies that, if the price of beef cattle increases by one unit, beef cattle marketable supply increased by 0.6692 . This is in line with the results of previous studies by (Dinku et al., 2019) price of paddy received by farmers affects marketable surplus of crops positively.

Access to market information system (AMI): the result of estimated coefficient of this variable affects marketable supply of beef cattle positively at $5 \%$ level of significance. This means as the farmer access to market information increase by one unit, marketable supply of beef cattle increased by 0.6985 . This result goes with (Gemechu et.al, 2020) factor affecting beef cattle value chain analysis.

Access to credit (ATC): beef cattle marketable supply affected positively at $1 \%$ significance level. Being access to credit, increase marketable supply by 1.022 . This study in line with (Gemechu et al., 2020) factor affecting beef cattle value chain analysis.

\section{Conclusion and recommendations}

As multiple linear regression model result indicate: marketable supply of beef cattle was affected positively by: number of livestock fattened, sex of household head, perception of current price, access to credit, and area of land allocated for grazing, access to market information and educational status. As a result, those factors have to be promoted by concerned body through facilitation of agricultural inputs including credit service, education, and extension service to increase beef cattle marketable supply in the study area. The result recommended that: 
development of fattening management systems should be taken in to consideration by development agents, governmental and non-governmental organizations', to create awareness for beef cattle production and marketable supply of beef cattle sectors.

Abbreviations: CSA: Central Statics Agency, GDO: Gimbo District Office, MLRM: Multiple Linear Regression Model

Availability of data

The raw data which confirm the output of this study can be found from the author based on permissible request. Competing interests

There are no competing interests.

Funding

Authors have not gotten direct fund for this research work.

Authors' contributions

Plan, analysis and revision of this paper were done by this author.

Acknowledgements: I would like to thank Bonga University and my staff members by their technical support. Moreover, I thank the target respondents and district experts for their valuable response during data collection process.

Author information: Gedefaw Abebe is lecturer of Agricultural Economics at Bonga University of Kaffa Zone, Southern Nation Nationality Regional States, Ethiopia. The author received his first BSc degree from University of Gondar in Agricultural Economics on 2016. After successfully completed his study, he joined Arba Minch University same year to pursue his MSc degree on Agricultural Economics and completed on 2018 his study with very good academic result. Then, he joined Bonga University and has been serving as instructor and researcher. His overall research interest falls within the domain of wider agricultural economics problem such as market chain analysis, market outlet choice analysis, adoption of agricultural change and others problems related to enhancement of overall production and productivity of agricultural sector.

\section{References}

Abebe Birara Dessie, Tigabu Dagnew Koye, Abebe Dagnew Koy and Asmamaw Alemu Abitew. (2019). Analysis of red pepper marketing: evidence from northwest Ethiopia. Journal of economic structure, 8:24.

Amistu K., Temesgen M., Alemu A., Tarekegn W. (2016). Assessment of Beef Cattle Fattening and Marketing System and Contribution to Household Food Security in Case of Lemmo Woreda, Hadiya Zone, Southern Ethiopia. Journal of Marketing and Consumer Research, 29(2016).

CSA. (2013). The 2001/02 Ethiopian Agricultural Sample Enumeration (ESAE). Addis Ababa, Ethiopia: In: New Partnership for Africa's Development (NEPAD) - Comprehensive Africa Agriculture Development Programme (CAADP) Ethiopia: Investment Project Profile "Live Animal.

CSA. (2014). Ethiopian population sensus In 2014

D, G. (2004). Basic Econometrics. United States Military Academy, West Point: Tata McGraw-Hill.

Dinku A, Abebe B, Lemma A, Shako M. (2019). Beef cattle value chain analysis: Evidence from West Hararghe Zone of Ethiopia. Int J Agric Sc Food Technol, 5(1), 077-087.

Eyob Eshetu, Zewudu Abraham. (2016). Review on live animal and meat export marketing system in Ethiopia: challenges and opportunities. Journal of Scientific and Innovative Research, 5(2), 59-64.

G.Cochran, W. (1963). Sampling Techniques. (2nd Ed., Ed.) New York: John Wiley and Sons, Inc.

Gemechu Degefa Yadata (M.Sc.), Adeba Gemechu (PHD), Amsalu Mitiku (PhD) (2020). (2020). Factor Affecting Beef Cattle Value Chain Analysis in Nono Benja District, Jimma Zone, Oromia Regional State, Ethiopia. Journal of Biology, Agriculture, Vol.10(No.3).

Gezehagn Gesese, Teshale Woldeamanueal, Belayneh Legesse. (2019). Determinants of Market Participation and Supply of Beef Cattle Value Chain in Konso District, Southern Nations, Nationalities and Peoples' Region, Ethiopia. Vol.83, 2019.

Greene, W. (2003). Econometric analysis. Delhi: Pearson Education India.

Gujarati, D. (2004). Basic Econometrics. United States Military Academy, West Point: Tata McGraw-Hill.

H.D.Utamietal. (2018). Determinants Affecting on Smallholder Madura Cattle Farming at Pamekasan Regency, East Java, Indonesia. IOP Publishing.

Kaya.U , Guler. N. (2013). A study on multiple linear regression analysis. ELEVIER, 106((2013)), 234-240.

Lemma Zemedu, Berhanu Gebremdhin, Solomon Ayele1. (2019). Determinants of Beef cattle Market Participation Decision by Smallholder Farmers in Dugda and Bora Districts, Oromia Regional State, Ethiopia. Journal of Natural Sciences, Vol.9(No.20).

Maddala GS, Lahiri K. (1992). Introduction to econometrics (Vol. vol 2). New York, Macmillan.

Motta P, Porphyre T, Handel IG, Hamman SM, Ngu Ngwa V, Tanya VN, Morgan KL and Bronsvoort BMdC. (2019). Characterizing Livestock Markets, Primary Diseases, and Key Management Practices Along the Livestock Supply Chain in Cameroon. Front. Vet. Sci, 6:101. 
Motta P, Porphyre T, Handel IG, Hamman SM, Ngu Ngwa V, Tanya VN, Morgan KL and Bronsvoort BMdC. (n.d.). Characterizing Livestock Markets, Primary Diseases, and Key Management Practices Along the Livestock Supply Chain in Cameroon. Front. Vet. Sci, 6:101.

Ponguru CS Reddy , NagallaVidya Kanna. (2015). Market and Value Chain Analysis of Cattle and Beef in Ethiopia -A Review. International Journal of Social Sciences, Arts and Humanities, 1(2), 51-66.

Shumetie \& Mamo. (2019). Effect of cropland and livestock ownership on child labour in eastern Ethiopia: empirical examination of the Wealth Paradox. international journal of child care and educational policy, 13(5).

Sicelo Ignatius Dlamini , and Wen-Chi Huang. (2019). A Double Hurdle Estimation of Sales Decisions by Smallholder Beef Cattle Farmers in Eswatini. Sustanability, 11, 5185.

Sitti Nurani Sirajuddin, et al 2015. (2015). Value Added Analysis of Beef Cattle Supply Chain Actors Micro-Scale Community Farm Based. AMERICAN-EURASIAN JOURNAL OF SUSTAINABLE AGRICULTURE, 7-12.

Tamrat, D. (2019). Beef Cattle Supply Status with Recent Trends and Future Prospects in Relation to Past in the Cases of Mechara Town, West Hararghe, Oromia Regional State. Journal of Biology, Agriculture and Healthcare, 9(5).

Tekeba Eshetie, Kelifa Hussien, Tadesse Teshome, Abebaw Mekonnen. (2018). Meat production, consumption and marketing tradeoffs and potentials in Ethiopia and its effect on GDP growth: a review article. Journal of Nutritional Health \& Food Engineering, Volume 8 Issue 3-2018.

Wenying Li, Yunhan Li and Jeffrey H. Dorfman. (2019). Dynamically Changing Cattle Market Linkages with Supply-Side-Controlled Transitions, Cambridge University press. Journal of Agricultural and Applied Economics, 2019(52), 472-484.

Zekarias Bassa ,Teshale Woldeamanuel. (2018). Determinants of cattle Market Participation Decision by Pastoralist in Southern Ethiopia: The case of Moyale district in Borana zone of Oromiya Region. International journal of environmental science and natural resources, research article volume 13( Issue 4). 